\title{
Treatment to lipid targets in patients with inflammatory joint diseases in a preventive cardio-rheuma clinic
}

\author{
S Rollefstad ${ }^{1}$, TK Kvien ${ }^{12}$, I Holme ${ }^{2}$, AS Eirheim ${ }^{1}$, TR Pedersen ${ }^{3}$, AG Semb ${ }^{1}$ \\ ${ }^{1}$ Department of Rheumatology, Diakonhjemmet Hospital, Oslo, Norway \\ ${ }^{2}$ University of Oslo, Oslo, Norway \\ ${ }^{3}$ Unit of biostatistics and epidemiology, Oslo University Hospital, Ullevål, Oslo, Norway \\ ${ }^{4}$ Centre of Preventive Medicine, Oslo University Hospital, Ullevål, Oslo, Norway
}

Disclosure statement: S. Rollefstad and A. S. Eirheim have no disclosures. T. K. Kvien has received speaker and/or consulting honoraria and/or research grants from Abbott, BMS, Merck/Schering-Plough, Pfizer/Wyeth, Roche, and UCB. I. Holme has received speaker honoraria and consulting fees from Pfizer and Merck/Schering Plough and consulting fees from AstraZeneca and Roche. T. R. Pedersen has received speaker honoraria and consulting fees from Pfizer and Merck/Schering-Plough and speaker honoraria from AstraZeneca. A. G. Semb has received speaker honoraria from Merck/Schering Plough, Abbott, Pfizer, BMS and Wyeth, and received speaker honoraria and consulting fee from Abbott and Roche.

Key words: Rheumatoid Arthritis, Ankylosing Spondylitis, Psoriatic Arthritis, cardiovascular disease, lipids

Short title: Lipid targets in a preventive cardio-rheuma clinic

Word count: 2998

Abstract: 249 words

Corresponding author:

A. G. Semb, MD, PhD,

Department of Rheumatology,

Diakonhjemmet Hospital,

P.O. Box 23 Vinderen,

NO-0319 Oslo, Norway,

Tel: +47 22451500,

Fax: +47 22451777,

Email: a-semb@diakonsyk.no 


\begin{abstract}
Objectives: To perform cardiovascular (CV) risk stratification in patients with inflammatory joint diseases (IJD) and treat to lipid targets according to recommendations.

Methods: We initiated a preventive cardio-rheuma clinic based on the unmet need of adequate CV prevention in IJD patients. A full CV risk stratification was performed at the first consultation (history of conventional risk factors and of CV disease, lipid measurement, blood pressure and ultrasound examination of both carotid arteries), and the patient was classified to either a primary or secondary CV prevention regime, or to have low risk (no intervention). Lipid lowering (LL) treatment was adjusted until at least two lipid targets were achieved.
\end{abstract}

Results: Of the 426 patients referred, $36.6 \%$ had a systematic coronary risk evaluation (SCORE) $<5 \%$ (no LL intervention). The remaining 270 patients [(rheumatoid arthritis (RA): $n=165$, ankylosing spondylitis (AS): $n=70$, and psoriatic arthritis (PsA): $n=35$ ] were categorized to either primary $(n=63)$ or secondary prevention $(n=207)$. There were significant differences between the patient groups regarding age $(p<0.001)$, sex $(p<0.001)$ and disease duration $(p<0.001)$. Lipid changes in IJD patients were; total cholesterol: $1.86 \pm 1.20 \mathrm{mmol} / \mathrm{L}$ $(p<0.001)$, low density lipoprotein cholesterol: $1.74 \pm 1.11(p<0.001)$, high density lipoprotein cholesterol: $-0.01 \pm 0.30(p=0.61)$, triglycerides: $0.28 \pm 0.72(p<0.001)$. The proportions of patients reaching at least 2 lipid targets were for RA/AS/PsA: 92.1/90.0/82.9\% respectively. No serious adverse events were observed.

Conclusions: There was indication for CV prevention in a high proportion of IJD patients referred for $\mathrm{CV}$ risk stratification. Treatment to lipid targets was successful in approximately $90 \%$ of patients with IJD. 


\section{Introduction}

In industrialized countries cardiovascular (CV) disease is the number one cause of death and $\mathrm{CV}$ prevention programs have been evolved. There is no longer doubt that patients with inflammatory joint diseases (IJD) have an increased risk of CV disease. Within the IJD group, patients with rheumatoid arthritis (RA) have been most extensively investigated concerning $\mathrm{CV}$ risk, ${ }^{12}$ but the $\mathrm{CV}$ burden of patients with psoriatic arthritis $(\mathrm{PsA})^{34}$ and ankylosing spondylitis $(\mathrm{AS})^{56}$ has also been documented to be increased compared to the general population. RA is associated with the same risk of myocardial infarction as patients with diabetes mellitus. ${ }^{1}$ In the latest European Society of Cardiology's (ESC) guidelines for CV disease prevention, ${ }^{7}$ immunological diseases like RA is for the first time mentioned as a high risk factor. RA alone is not an indication for lipid lowering (LL) treatment, but is recommended to be taken into consideration as a part of the $\mathrm{CV}$ risk stratification.

For several decades the increased CV risk in IJD has been known, but this knowledge has not been implemented into clinical practice. There is still a lack of CV hard end point trials for this patient group, although some post hoc analyses from large placebo controlled trials with CV outcome have reported that patients with IJD have comparable cardio-protective effect of statins as those without IJD. ${ }^{89}$

A multicenter audit recording $\mathrm{CV}$ risk in patients with RA and systemic lupus erythematosus concludes that $\mathrm{CV}$ risk factors are inadequately managed in these diseases. ${ }^{10}$ Furthermore, Toms et al reported that there was a substantial undertreatment of $\mathrm{CV}$ risk in patients with RA. ${ }^{11}$ Thus, there is an unmet need of systematic CV prevention in patients with IJD. We have initiated a preventive cardio-rheuma clinic for patients with IJD. The objective of this report is to evaluate the proportion of patients with IJD in need of CV prevention, and the clinical effects of the LL therapy with regard to achievement of guideline recommended lipid targets.

\section{Patients and methods}

Patients with IJD were referred for CV risk stratification from a rheumatology out patient clinic or from general practitioners, to the Preventive Cardio-Rheuma clinic during the period March 2009 and July 2012. Referral criteria were diagnosed IJD, age between 25 and 85 years and fulfilment of at least one of the following criteria: Known CV risk factor(s), symptoms/signs of a risk factor, familial premature $\mathrm{CV}$ disease or simply that a patient wished to undergo $\mathrm{CV}$ risk stratification. At the first consultation $\mathrm{CV}$ risk stratification was performed. The patient was classified to either primary or secondary CV prevention with LL treatment, or to have low risk with no indication for medical intervention. LL treatment was 
adjusted until at least two lipid targets were achieved (or at the nearest possible level of the lipid targets).

\section{Recording of CV risk factors}

When the patients received a letter regarding date/time for the consultation, they also received a CV questionnaire, which was completed and returned at the consultation. The following risk factors were recorded: Smoking status, diabetes, medication history, family history of premature $\mathrm{CV}$ disease in first degree relatives (male/female $<55 /<65$ years) and presence of established CV disease as well as history of stroke, transient ischemic attack, or peripheral vascular disease.

Laboratory tests included total cholesterol (TC), high density lipoprotein cholesterol (HDL-C), triglycerides (TG), low density lipoprotein cholesterol (LDL-C), liver enzymes, creatine kinase $(\mathrm{CK})$, creatinine, haemoglobin and C-reactive protein (CRP). All were measured at the hospital laboratory (European standard Accredited 2009) by routine procedures in a COBAS $600 .{ }^{12}$ The erythrocyte sedimentation rate (ESR) was analysed by the Westergren method.

Brachial blood pressure (BP) was measured using an Omron M7 after a 5 minute rest in a supine position. If the BP exceeded 140/90, three consecutive measurements were done and a mean was calculated. A twelve lead electrocardiogram was recorded digitally.

Bilateral B-Mode ultrasonographic examination of the carotid arteries was performed with a Vivid-7 ultrasound scanner (General Electrics Vingmed Ultrasound) using a $12 \mathrm{MHz}$ probe $(9-14)$ linear matrix array transducer. The ultrasonographic examinations were all performed by one sonographer (AE) supervised by a cardiologist (AGS). Atherosclerotic plaque(s) in the common carotid artery, bulb and the internal carotid artery in the far and near wall were identified. This was performed by revealing protrusions $\geq 1.4 \mathrm{~mm}$ into the lumen or more than a doubling of the adjacent intima-media thickness, when both intimamedia of the far and near wall had sharp edges in the longitudinally view. If there was any doubt about the plaque, it was verified by a cross sectional image by turning the probe $90^{\circ}$ to the longitudinal axis of the vessel. ${ }^{13}$

\section{Management of $\mathrm{CV}$ risk factors}

All patients received advices about cholesterol friendly food choices (including a brochure) and physical activity. Smokers were advised to stop and were offered the opportunity to join smoking cessation support programmes and/or use of appropriate medications. Patients with diabetes in need of optimized glucose control were referred to an outpatient diabetic clinic. If anti-hypertension treatment was initiated the BP goals were $<140 / 90 \mathrm{mmHg}$, or $125 / 80$ $\mathrm{mmHg}$ in a 24-hour recording. 


\section{Primary prevention}

Individual $\mathrm{CV}$ risk stratification was done by using the systematic coronary risk evaluation (SCORE) for high risk countries ${ }^{14}$ which is recommended by the ESC. Patients without established CV disease with a SCORE $\geq 5 \%$ (10 year risk of fatal myocardial infarction), received LL treatment. The lipid goals were as follows: $T C \leq 4.5 \mathrm{mmol} / \mathrm{L}$, $\mathrm{LDL}-\mathrm{c} \leq 2.5 \mathrm{mmol} / \mathrm{L}$, $\mathrm{HDL}-\mathrm{C} \geq 1.0 / 1.2 \mathrm{mmol} / \mathrm{L}$ for males/ females, $T G \leq 1.7 \mathrm{mmol} / \mathrm{L}$. In this paper we refer to these lipid levels as targets. However, lower HDL-c or higher TG levels than mentioned are described as markers of increased risk, but there is not sufficient evidence to consider these specific levels of HDL-c and TG as recommended targets according to the ESC guidelines. ${ }^{7}$

\section{Secondary prevention}

Patients in the very high risk group are, according to the latest ESC guidelines for CV prevention, ${ }^{7}$ those with documented $\mathrm{CV}$ disease by invasive or non-invasive testing, previous myocardial infarction, acute coronary syndrome, coronary/arterial revascularization, ischemic stroke, peripheral artery disease, diabetes mellitus with one or more $\mathrm{CV}$ risk factors and/or target organ damage, and patients with severe chronic kidney disease. A calculated SCORE $\geq 10 \%$ also indicates a very high risk for $C V$ disease. These patients have the highest priority for treatment, and the recommended lipid targets are lower. We implemented the following lipid goals: $\mathrm{TC} \leq 4.0 \mathrm{mmol} / \mathrm{L}, \mathrm{LDL}-\mathrm{C} \leq 1.8 \mathrm{mmol} / \mathrm{L}$ or a $\geq 50 \%$ reduction from baseline $\mathrm{LDL}-\mathrm{c}$ if the LDL-c goal $\leq 1.8 \mathrm{mmol} / \mathrm{L}$ could not be obtained. HDL-c and TG goals were the same as in primary prevention.

\section{Follow up until treatment goals were reached}

The cardiologist initiated the LL intervention with statins and continued or changed the LL treatment until at least two lipid targets were achieved (or at the nearest possible level of the lipid targets), before the patients were discharged for further follow up by the general practitioner.

\section{Statistics}

The data are presented as crude data and the results are expressed as mean $\pm S D$ and median (IQR) for normally and non-normally distributed characteristics, respectively. The data were compared using paired samples t-test, ANOVA-, Kruskal-Wallis- and $X^{2}$ - tests as appropriate. Data analyses were performed using IBM SPSS V20.

\section{Results}




\section{Patient characteristics}

Four hundred and twenty six patients with IJD (RA $n=257$, AS $n=108$ and PSA $n=61$ ) were referred to the Preventive Cardio-Rheuma clinic (figure 1). Patients with RA were older than the other patient groups, $p<0.001$ (table 1 ). The RA patients were mostly female $(73.2 \%)$ and the majority of the AS patients were as expected men (68.5\%). In the PsA patient group the gender distribution was more equal (female 55.7\%). The median disease duration was about 15 years in patients with RA and PsA, but 22.5 years in AS patients. As expected, the PsA patients had a slightly higher body mass index $(p=0.003)$. Approximately $6-10 \%$ of all the patients had established CV disease (RA 9.7\%, AS 10.2\%, PsA 6.6\%) (table 1). The lipid profile in IJD patients was comparable, although there was a significant difference in HDL-C between the groups $(p<0.001)$, possibly due to more females in the RA population. Almost half of all referred patients had atherosclerotic plaque(s) in the carotid arteries (CP) (RA $46.3 \%$, AS $44.4 \%$, PsA $41 \%$ ). Despite established CV disease, or CP on ultrasound, a high proportion of patients were not using LL treatment at baseline (RA 81.0\%, AS 83.3\%, PsA $64.3 \%)$.

\section{Cardiovascular risk stratification}

Of the 426 patients, 270 were categorized to preventive LL treatment (63.4\%) (figure 1). The proportions of patients having a SCORE $\geq 5 \%$ (categorized to primary prevention) were not similar across the patient groups (RA/AS/PsA: $13.6 \% / 16.4 \% / 14.3 \%, p=0.80$ ). More than $3 / 4$ (76.7\%) of the patients in need of LL intervention had either CV disease, CP or both, and were categorized to secondary preventive treatment.

\section{Treatment to target}

Indication for LL intervention was found in approximately $60 \%$ of all the referred patients. Initiation of LL treatment was done with statins (atorvastatin, simvastatin, rosuvastatin or pravastatin). Patients reaching at least two lipid targets were for RA $92.1 \%$, AS 90.0\%, and for PsA $82.9 \%$ (figure 2). In the combined IJD group, $40.4 \%$ reached all 4 lipid targets, $30.4 \%$ reached 3 lipid targets and $19.6 \%$ only obtained 2 of the targets. LL treatment was unsuccessful in 26 patients (9.6\%) and there were various reasons for this. Two patients did not reach lipid targets at the highest possible dose of statins. Three patients did not reach lipid goals, but were so close to targets that the lipid profile was accepted by the cardiologist. One patient had an unacceptable CK increase and two patients had a rise in the liver enzymes, and statin treatment was stopped. The increase in liver enzymes and CK was not $\geq 3$ times upper normal limit. Five patients died ( $n=4$ outside the hospital, $n=1$ of colon cancer with liver metastasis), one patient was diagnosed with lymphoma and was lost to follow up. Nine patients preferred follow-ups by their general practitioner, one did not want to take 
statins and another patient did not obtain targets due to poor compliance. After a carotid endarterectomy, one patient was followed by the vascular surgery clinic at Oslo University Hospital, and was therefore lost to follow up at the Preventive Cardio-Rheuma clinic. Some patients did experience tolerable minor side effects like muscle tenderness or symptoms from the gastrointestinal tract. These were not recorded systematically in our clinical setting, if the statin treatment were not changed. There were no serious adverse events concerning statin medications. The patients needed on average less than 3 consultations to reach at least two lipid targets.

\section{Lipid attainment in primary prevention}

A total of $23.3 \%$ of the patients were in need of $L L$ intervention and were categorized to primary prevention (figure 1). Baseline TC and LDL-C were higher in RA compared to AS and PsA ( $p=0.17$ and $p=0.11$ respectively). Before the patients were discharged for further follow up by the general practitioner, the lipid profile were lower than or at target values in all patients, except for TG in PsA (table 2). Twenty percent of the PsA patients, who were categorized to $L L$ intervention, had combined dyslipidaemias, which includes elevated TG and low HDL-c levels. This may have influenced the incompleteness of reaching the TG targets. In the combined patient group; IJD, there was a significant change in all lipids from first to final consultation, except for HDL-c (figure 2). When evaluating the 3 patient groups separately, there was not a significant change in LDL-c in patients with PsA concerning primary prevention (table 2). This may be a reflection of the low number of PsA patients $(n=9)$. There was no significant change in TG levels among AS and PsA patients. As in the combined IJD group, HDL-c did not change significantly for RA, AS and PsA patients (table 2). The proportion of patients categorized to primary prevention reaching each lipid target was for TC: $60.3 \%$, LDL-C: $66.7 \%$, HDL-C: $82.5 \%$ and TG: $69.8 \%$ (figure 3).

\section{Lipid attainment in secondary prevention}

Baseline lipids were lower in patients who had established CV disease and who were categorized to secondary preventive treatment, compared to patients categorized to primary prevention (table 2). This was probably due to that some patients [RA $n=8(14.0 \%), A S n=7$ $(13.5 \%)$ and PsA $n=8(30.3 \%)]$ were already statin users when referred to the clinic, although the statin dosage was inadequate for reaching recommended lipid targets. These patients were also included into the analysis, because one of our aims was to evaluate whether attainment of lipid targets were possible. For all the patient groups, the final mean levels for LDL-C, HDL-C and TG were under or at goal values except for TC which were closely at target (table 2). This was only so for patients with RA and was due to the higher HDL-c in this patient group. The percent change in lipids from first to final consultation was significant 
except for HDL-c, as in primary prevention, in the combined IJD group (figure 2) and for the separate patient groups; RA, AS and PsA (table 2). The proportion of patients with secondary prevention goals reaching each lipid target was for TC: $57.0 \%$, LDL-C: $73.9 \%$, HDL-c: $83.1 \%$ and TG: $81.2 \%$ (figure 3 ).

Overall, lipid targets were reached in approximately $90 \%$ of all 3 patients groups combined (figure 4), using on average less than 3 consultation to obtain this. When being referred to the clinic, $12.9 \%$ of the patients were already using a statin, but had not reached lipid targets. This did not influence the number of consultations needed to obtain lipid goals, because patients who used statins when referred needed on average $2.80 \pm 1.10$ vs.

$2.70 \pm 1.19$ consultations for patients who did not use statins $(p=0.62)$ to obtain lipid targets.

\section{Discussion}

In 426 patients referred to $\mathrm{CV}$ risk stratification, more than $60 \%$ were in need of $\mathrm{LL}$ intervention. Of these, two thirds were categorized to intensive $L L$ treatment and one third to primary prevention. The lipid targets were not reached in $10 \%$ of the patients. On average, only three consultations were needed to obtain 2 recommended lipid goals.

In the general population approximately $40 \%$ have been reported to obtain lipid targets. ${ }^{1516}$ This was to a great extent due to suboptimal use of $L L$ treatment. There are several potential reasons for this unsuccessful result. Physicians may be concerned about possible side effects or that increasing statin doses only result in marginal LL effect, and there is the issue of compliance. In our report a very high proportion of the patients reached recommended goals, but over time this goal attainment may be lower. Future studies are warranted to reveal this. Lindhardsen et al also reported that physicians less often initiate secondary prevention in RA patients compared to non-RA patients, with statins being the most underused drugs. ${ }^{17} \mathrm{~A}$ high number of our patients did not receive $L L$ treatment at baseline despite established $\mathrm{CV}$ disease or asymptomatic $\mathrm{CP}$. These patients have a very high risk for future fatal myocardial infarction. ${ }^{718}$

Patients with IJD have a systemic inflammation and lower lipids compared to the general population. Hypothetically, the systemic inflammation may be a reason for the need of higher statin doses to obtain the same LL effect as the general population. Contradicting this is the lower lipid levels. These factors illuminate the difficulties in CV risk stratification and prevention in IJD patients. Recent published data indicates that the LL effect of statins in RA, AS and PsA patients are comparable to non-IJD patients. ${ }^{9} 19$

Patients with IJD have a severe chronic and disabling disease, and for that reason often use several medications. Polypharmacy increases the risk of drug interactions, and may therefore potentially give more side effects. We did not observe this in our patients, which fall in line with the recently reported comparable side effects by statins in patients with 
and without IJD. ${ }^{919}$ Although, the patients with IJD had somewhat more side effects from the gastro intestinal tract.

Our focus has been to evaluate the CV risk in IJD patients, and initiate optimal preventive treatment when needed in accordance with guidelines for the general population. Ultrasound of the carotid arteries has been an important part of the risk stratification as we found that almost half of the patients had asymptomatic CP.

RA patients have a significantly shortened life expectancy, which is mainly due to CV disease. ${ }^{20} 21$ The background inflammation is most likely an important reason for the substantially increased risk of CV disease in RA. Statins reduces the systemic inflammation in addition to the LL effect, ${ }^{22-25}$ and has been shown to reduce joint inflammation in RA. ${ }^{26}$ Furthermore, statins may have a beneficial effect on endothelial function, ${ }^{22}$ arterial stiffness ${ }^{27}$ and in improving HDL-c anti-inflammatory properties in patients with RA. ${ }^{28} \mathrm{~A}$ costeffectiveness analysis concludes that the dual effect of statins (LL and anti-inflammatory) makes this therapy highly cost effective in RA patients. ${ }^{29}$ Hypothetically this would also apply for AS and PsA patients.

A placebo controlled study (TARA) showed that treatment with atorvastatin $40 \mathrm{mg}$ resulted in a reduction in CRP and ESR, and a significant lower swollen joint count compared to placebo. ${ }^{26}$ Due to our CV focus, swollen joint count was not recorded and thus we could not relate statins to disease activity. This is an observational report, and not as well controlled as experimental studies, which is an obvious limitation.

Strengths of our clinical data are the relatively large number of IJD patients and that all have been treated by the same physician. A further strength is that the 3 patient groups were comparable regarding $\mathrm{CV}$ risk factors.

In conclusion, more than $60 \%$ of IJD patients who were referred to $\mathrm{CV}$ risk stratification were in need of preventive treatment with statins, supporting the importance and relevance of establishing preventive cardio-rheuma clinics. Of these patients, $90 \%$ obtained lipid targets in less than three consultations. No serious adverse side effects were observed. Our data illustrate that LL medication as statins are effective and safe in patient with IJD. Longitudinal data are needed to demonstrate whether LL in patients with IJD also can reduce the risk of CV disease and outcome. 
Table 1 Baseline characteristics

\begin{tabular}{|c|c|c|c|c|}
\hline & RA & AS & PsA & $p$-value \\
\hline Number $n$ (\%) & $257(60.3)$ & $108(25.4)$ & $61(14.3)$ & - \\
\hline Age median (IQR) & $60.0(52.0-67.0)$ & $55.5(47.0-63.8)$ & $56.0(48.0-62.0)$ & $<0.001$ \\
\hline Sex male/female $n(\%)$ & $\begin{array}{c}69 / 188 \\
(26.8) /(73.2)\end{array}$ & $\begin{array}{c}74 / 34 \\
(68.5) /(31.5)\end{array}$ & $\begin{array}{c}27 / 34 \\
(44.3) /(55.7)\end{array}$ & $<0.001$ \\
\hline Disease duration median (IQR) & $15.0(5.0-22.0)$ & $22.5(12.0-31.3)$ & $14.0(2.0-25.0)$ & $<0.001$ \\
\hline \multicolumn{5}{|l|}{ CV risk factors } \\
\hline Smoke $n(\%)$ & $42(16.3)$ & $21(19.4)$ & $8(13.1)$ & 0.56 \\
\hline $\mathrm{BMI}$ mean $\pm \mathrm{SD}$ & $25.71 \pm 4.60$ & $25.66 \pm 3.90$ & $26.95 \pm 5.85$ & 0.003 \\
\hline Number of $\mathrm{CP}$ median (range) & $0(0-8)$ & $0(0-5)$ & $0(0-4)$ & 0.80 \\
\hline $\mathrm{TC}(\mathrm{mmol} / \mathrm{L})$ mean $\pm \mathrm{SD}$ & $5.81 \pm 1.23$ & $5.55 \pm 1.13$ & $5.72 \pm 1.21$ & 0.17 \\
\hline HDL-C (mmo/lL) mean $\pm S D$ & $1.77 \pm 0.55$ & $1.51 \pm 0.52$ & $1.62 \pm 0.61$ & $<0.001$ \\
\hline TG (mmo/L) median (IQR) & $1.1(0.8-1.5)$ & $1.2(0.9-1.7)$ & $1.3(0.9-2.0)$ & 0.11 \\
\hline LDL-C (mmo/lL) mean $\pm \mathrm{SD}$ & $3.48 \pm 1.02$ & $3.37 \pm 1.00$ & $3.47 \pm 1.08$ & 0.67 \\
\hline BP systolic $(\mathrm{mm} \mathrm{Hg}$ ) mean $\pm \mathrm{SD}$ & $139.48 \pm 21.12$ & $140.19 \pm 17.66$ & $142.13 \pm 20.21$ & 0.65 \\
\hline BP diastolic $(\mathrm{mm} \mathrm{Hg}$ ) mean \pm SD & $82.53 \pm 10.97$ & $82.06 \pm 10.84$ & $84.93 \pm 10.00$ & 0.23 \\
\hline \multicolumn{5}{|l|}{ Co morbidities n (\%) } \\
\hline HT & $143(55.6)$ & $58(53.7)$ & $36(59.0)$ & 0.80 \\
\hline Diabetes & $22(8.6)$ & $9(8.3)$ & $7(11.5)$ & 0.75 \\
\hline CV disease & $25(9.7)$ & $11(10.2)$ & $4(6.6)$ & 0.71 \\
\hline Carotid artery plaque & $119(46.3)$ & $48(44.4)$ & $25(41.0)$ & 0.72 \\
\hline CV disease total & $129(50.2)$ & $52(48.1)$ & $26(42.6)$ & 0.55 \\
\hline \multicolumn{5}{|l|}{ Lab mean $\pm S D$} \\
\hline $\mathrm{ESR}(\mathrm{mm} / \mathrm{h})$ & $21.6 \pm 17.9$ & $17.1 \pm 14.7$ & $15.7 \pm 11.3$ & 0.01 \\
\hline White blood cells $\left(10^{9} / \mathrm{L}\right)$ & $7.96 \pm 4.07$ & $7.23 \pm 1.75$ & $7.32 \pm 2.19$ & 0.52 \\
\hline CRP (mg/L) median (IQR) & $3.0(1.0-9.0)$ & $3.0(1.0-8.0)$ & $3.0(1.0-8.0)$ & 0.80 \\
\hline $\mathrm{Hb}(\mathrm{g} / 100 \mathrm{~mL})$ & $13.61 \pm 1.26$ & $14.23 \pm 1.15$ & $14.16 \pm 1.33$ & $<0.001$ \\
\hline Creatinine $(\mu \mathrm{mo} / \mathrm{L})$ & $68.89 \pm 15.48$ & $73.81 \pm 14.19$ & $70.48 \pm 15.09$ & 0.02 \\
\hline SGOT (U/L) & $28.90 \pm 13.49$ & $29.56 \pm 12.78$ & $29.31 \pm 9.78$ & 0.91 \\
\hline ALT (U/L) & $30.89 \pm 24.46$ & $31.49 \pm 20.57$ & $33.45 \pm 19.23$ & 0.74 \\
\hline CK (U/L) & $86.57 \pm 54.68$ & $131.72 \pm 203.78$ & $103.67 \pm 89.20$ & 0.01 \\
\hline \multicolumn{5}{|l|}{ Medication n (\%) } \\
\hline Prednisolon & 97 (37.7) & $9(8.3)$ & $11(18.0)$ & $<0.001$ \\
\hline NSAIDs & $95(37.0)$ & $52(48.1)$ & $28(45.9)$ & 0.10 \\
\hline DMARDs & $143(55.6)$ & $10(9.3)$ & $30(49.2)$ & $<0.001$ \\
\hline Biologics & $72(28.0)$ & $29(26.9)$ & $10(16.4)$ & 0.05 \\
\hline Statins & $31(12.1)$ & $12(11.1)$ & $11(18.0)$ & 0.39 \\
\hline HT medication & $63(24.5)$ & $26(24.1)$ & $10(16.4)$ & 0.31 \\
\hline
\end{tabular}

RA: rheumatoid arthritis, AS: ankylosing spondylitis, PsA: psoriatic arthritis, BMI: body mass index, CP: carotid plaques, TC: total cholesterol, HDL-c: high density lipoprotein cholesterol, TG: triglycerides, LDL-c: Low density lipoprotein cholesterol, BP: blood pressure, HT: hypertension, CV disease: cardiovascular disease (angina pectoris, myocardial infarction, percutanous coronary intervention, heart surgery, transitory ischeamic attack, stroke, peripheral artery disease), CV disease total: CV disease \pm carotid artery plaque, ESR: erythrocyte sedimentation rate, CRP: C-reactive protein, Hb: hemoglobin, SGOT: serum glutamic pyruvic transaminas, ALT: alanine aminotransferase, CK: creatine kinase, NSAIDs: non steroid antiinflammatory drugs, DMARDs: disease modifying antirheumatic drugs 
Table 2 Lipids at first and final consultation in patients categorized to LL treatment

\begin{tabular}{|c|c|c|c|c|c|c|c|c|c|}
\hline & \multicolumn{9}{|c|}{ First consultation } \\
\hline & \multicolumn{4}{|c|}{ Primary prevention } & \multicolumn{5}{|c|}{ Secondary prevention } \\
\hline & TC & HDL-C & TG & LDL-C & & TC & HDL-C & TG & LDL-C \\
\hline RA $(n=36)$ & $30 \pm 0.98$ & $1.94 \pm 0.58$ & $1.23(0.88-1.56)$ & $3.69 \pm 0.93$ & RA $(n=129)$ & $5.86 \pm 1.39$ & $1.77 \pm 0.58$ & $1.18(0.85-1.54)$ & $3.53 \pm 1.11$ \\
\hline AS $(n=18)$ & $89 \pm 1.40$ & $1.54 \pm 0.70$ & $1.55(1.23-2.04)$ & $3.49 \pm 1.29$ & 3( & $5.77 \pm 1.03$ & $1.55 \pm 0.51$ & $1.16(0.8 \mathrm{~s}$ & $3.54 \pm 0.94$ \\
\hline \multirow[t]{4}{*}{$\operatorname{PsA}(n=9)$} & $74 \pm 1.35$ & $1.26 \pm 0.35$ & $2.21(1.14-2.51)$ & $62 \pm 1.15$ & PsA ( & $5.82 \pm 1.26$ & $1.68 \pm 0.64$ & $1.36(0.89-1.91)$ & $3.51 \pm 1.25$ \\
\hline & \multicolumn{9}{|c|}{ Final consultation } \\
\hline & \multicolumn{4}{|c|}{ Primary prevention } & \multicolumn{5}{|c|}{\begin{tabular}{l|c|c}
\multicolumn{3}{c}{ Secondary prevention } \\
TC & HDL-c & TG
\end{tabular}} \\
\hline & TC & HDL-C & TG & LDL-C & & TC & HDL-C & TG & LDL-C \\
\hline RA $(n=36)$ & $4.51 \pm 0.97$ & $1.88 \pm 0.62$ & $1.06(0.82-1.37)$ & $2.09 \pm 0.61$ & RA $(n=129)$ & $4.08 \pm 0.75$ & $1.81 \pm 0.58$ & $0.96(0.78-1.42)$ & $1.77 \pm 0.50$ \\
\hline AS $(n=18)$ & $4.32 \pm 1.18$ & $1.47 \pm 0.61$ & $1.39(0.90-2.09)$ & $2.18 \pm 0.95$ & AS $(n=52)$ & $3.68 \pm 0.65$ & $1.55 \pm 0.50$ & $0.91(0.73-1.14)$ & $1.66 \pm 0.42$ \\
\hline \multirow[t]{4}{*}{ PsA $(n=9)$} & $4.45 \pm 0.52$ & $1.30 \pm 0.40$ & $1.85(1.05-2.56)$ & $2.31 \pm 0.40$ & PsA $(n=26)$ & $3.97 \pm 0.61$ & $1.63 \pm 0.46$ & $0.99(0.70-1.71)$ & $1.79 \pm 0.57$ \\
\hline & \multicolumn{9}{|c|}{ Change in lipids from first to final consultation } \\
\hline & \multicolumn{4}{|c|}{ Primary prevention } & \multicolumn{5}{|c|}{ Secondary prevention } \\
\hline & TC & HDL-C & TG & LDL-C & & TC & HDL-C & TG & LDL-C \\
\hline RA $(n=36)$ & $\begin{array}{l}1.79 \pm 1.11 \\
p<0.001\end{array}$ & $\begin{array}{c}0.06 \pm 0.26 \\
p=0.21\end{array}$ & $\begin{array}{c}0.11(-0.01-0.33) \\
\mathrm{p}=0.02\end{array}$ & $\begin{array}{l}1.60 \pm 0.98 \\
p<0.001\end{array}$ & RA (n=129) & $\begin{array}{c}1.84 \pm 1.17 \\
p<0.001\end{array}$ & $\begin{array}{c}-0.05 \pm 0.30 \\
p=0.11\end{array}$ & $\begin{array}{c}0.17(-0.06-0.37) \\
p<0.001\end{array}$ & $\begin{array}{c}1.80 \pm 1.09 \\
p<0.001\end{array}$ \\
\hline AS $(n=18)$ & $\begin{array}{c}1.64 \pm 1.82 \\
p=0.002\end{array}$ & $\begin{array}{c}0.06 \pm 0.35 \\
p=0.49\end{array}$ & $\begin{array}{c}0.23(-0.19-0.73) \\
p=0.17\end{array}$ & $\begin{array}{l}1.38 \pm 1.66 \\
p=0.004\end{array}$ & AS $(n=52)$ & $\begin{array}{l}2.13 \pm 1.03 \\
p<0.001\end{array}$ & $\begin{array}{c}-0.02 \pm 0.26 \\
p=0.61\end{array}$ & $\begin{array}{c}0.28(0.05-0.58) \\
p=0.001\end{array}$ & $\begin{array}{c}1.92 \pm 0.94 \\
p<0.001\end{array}$ \\
\hline PsA & $\begin{array}{c}1.30 \pm 1.16 \\
p=0.01\end{array}$ & $\begin{array}{c}-0.04 \pm 0.13 \\
p=0.34\end{array}$ & $\begin{array}{c}0.00(-0.24-0.39) \\
p=0.58\end{array}$ & $\begin{array}{c}1.32 \pm 1.17 \\
p=0.10\end{array}$ & Ps & $\begin{array}{c}1.85 \pm 1.23 \\
p<0.001\end{array}$ & $\begin{array}{l}0.05 \pm 0.35 \\
p=0.50\end{array}$ & $\begin{array}{c}0.10(-0.03-0.46) \\
p=0.04\end{array}$ & $\begin{array}{c}1.72 \pm 1.16 \\
p<0.001\end{array}$ \\
\hline
\end{tabular}

RA: rheumatoid arthritis, AS: ankylosing spondylitis, PsA: psoriatic arthritis, TC: Total cholesterol, HDL-c: High density lipoprotein cholesterol, TG: Triglycerides, LDL-c: Low density lipoprotein cholesterol 


\section{Figure Legends}

\section{Figure 1}

Patients referred to the Preventive Cardio-Rheuma clinic between March 2009 and July 2012 for cardiovascular risk stratification and treatment.

CP: Carotid plaque, CV disease: cardiovascular disease, SCORE: systematic coronary risk evaluation

\section{Figure 2}

TC: Total cholesterol, HDL: High density lipoprotein cholesterol, TG: Triglycerides, LDL: Low density lipoprotein cholesterol

\section{Figure 3}

TC: Total cholesterol, HDL: High density lipoprotein cholesterol, TG: Triglycerides, LDL: Low density lipoprotein cholesterol

\section{Figure 4}

RA: rheumatoid arthritis, AS: ankylosing spondylitis, PsA: psoriatic arthritis. The number of consultations is presented as mean \pm SD. 
Figure 1

\section{Preventive Cardio-Rheuma Clinic}

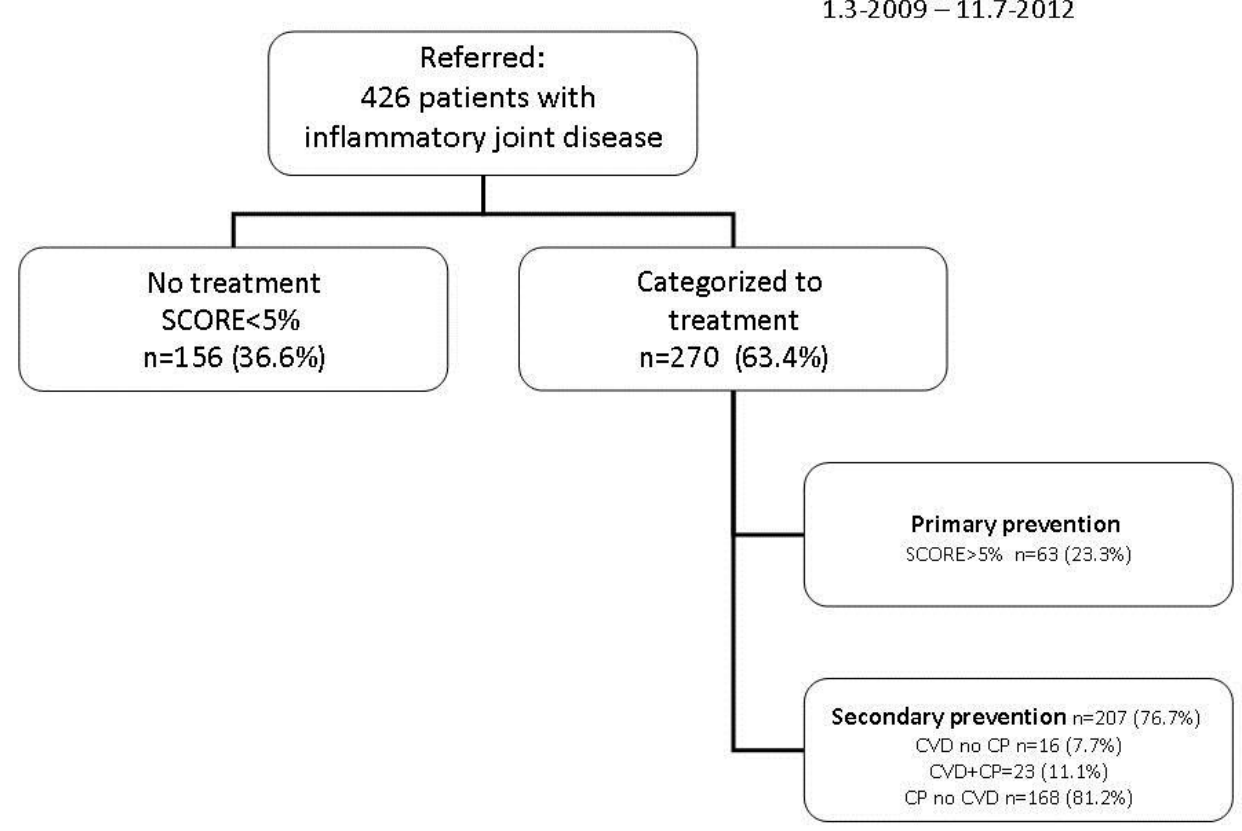


Figure 2

Percent change in lipids from first to final consultation

Primary prevention

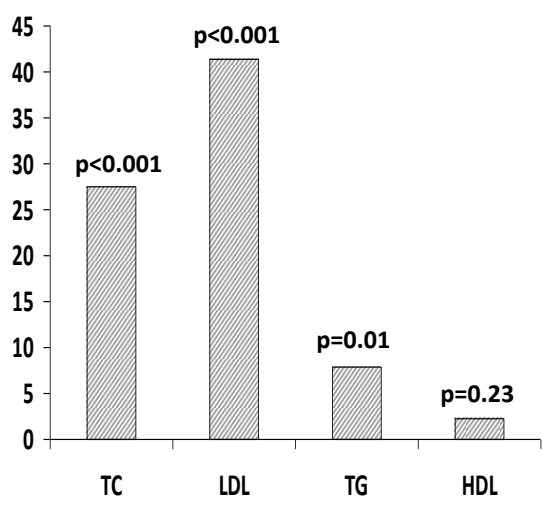

Secondary prevention

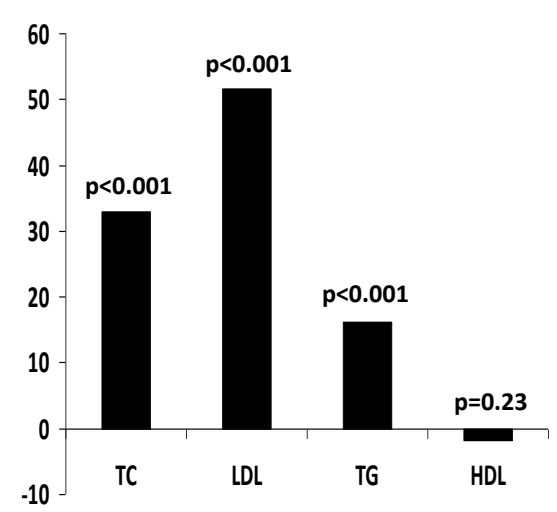


Figure 3

The proportion of patients reaching each lipid target

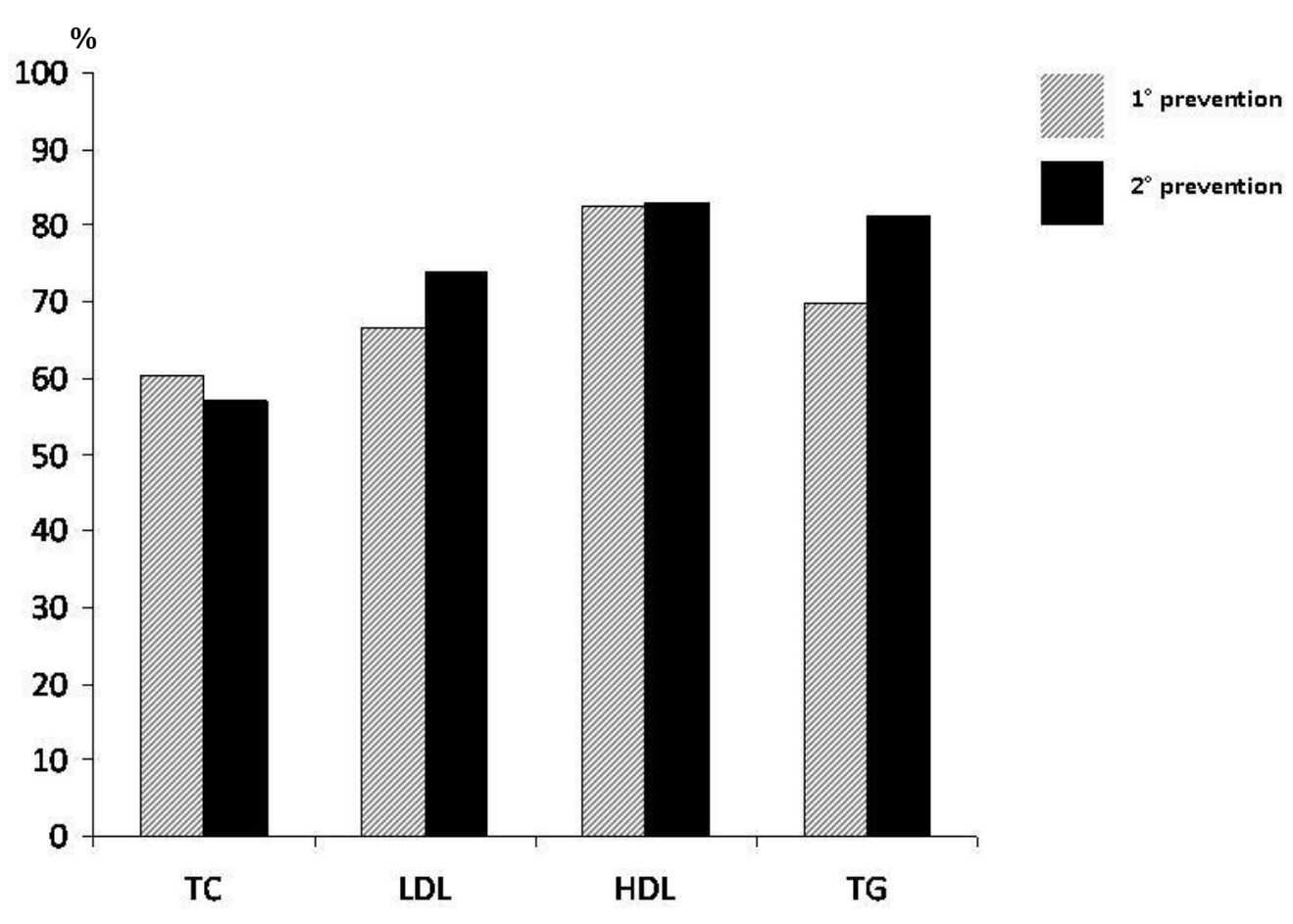


Figure 4

\section{Proportion of patients reaching}

at least 2 lipid targets

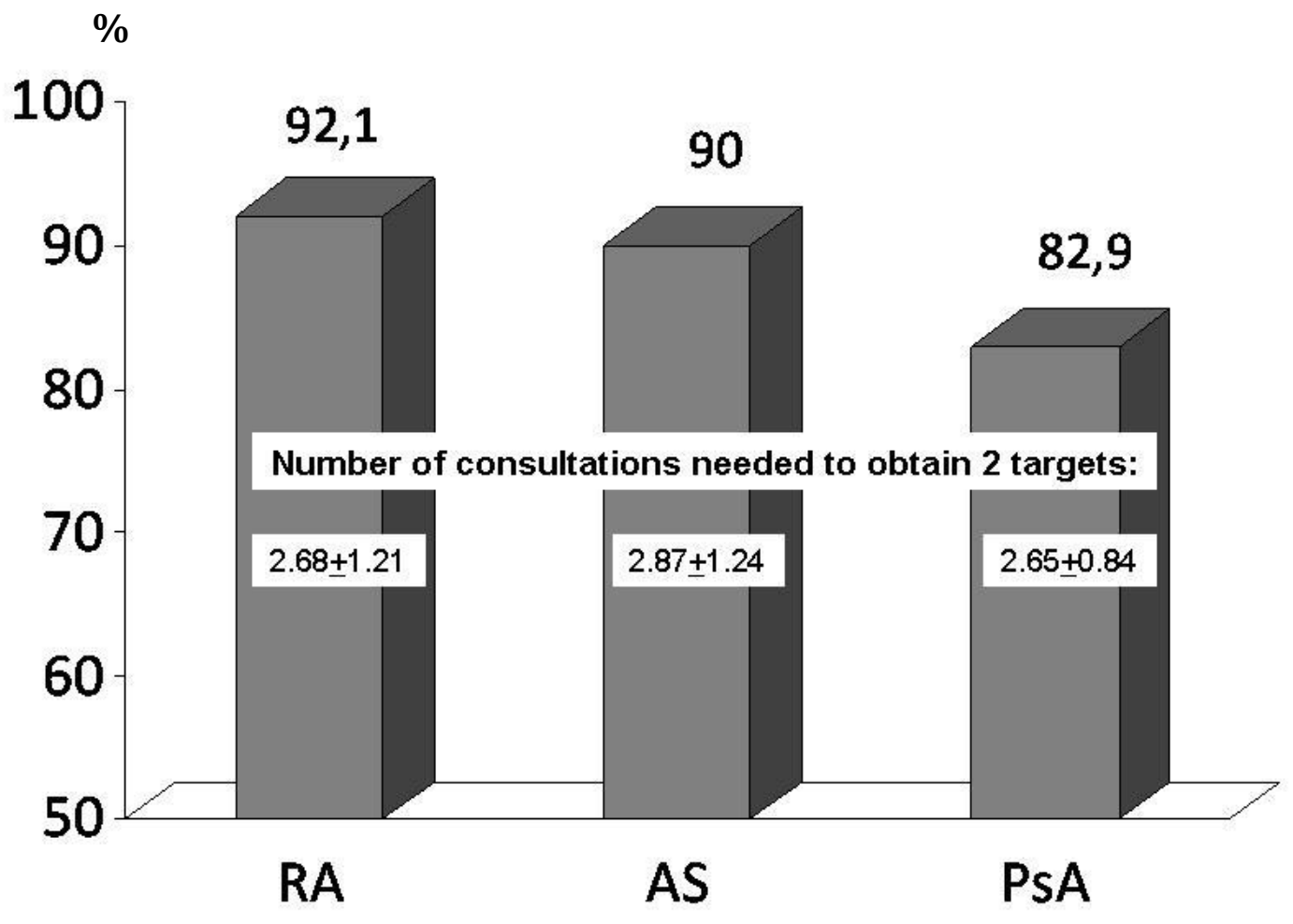




\section{Reference List}

(1) Lindhardsen J, Ahlehoff O, Gislason GH, Madsen OR, Olesen JB, Torp-Pedersen C et al. The risk of myocardial infarction in rheumatoid arthritis and diabetes mellitus: a Danish nationwide cohort study. Ann Rheum Dis 2011;70:929-934.

(2) Avina-Zubieta JA, Choi HK, Sadatsafavi M, Etminan M, Esdaile JM, Lacaille D. Risk of cardiovascular mortality in patients with rheumatoid arthritis: a meta-analysis of observational studies. Arthritis Rheum 2008;59:1690-1697.

(3) Han C, Robinson DW, Jr., Hackett MV, Paramore LC, Fraeman KH, Bala MV. Cardiovascular disease and risk factors in patients with rheumatoid arthritis, psoriatic arthritis, and ankylosing spondylitis. J Rheumatol 2006;33:2167-2172.

(4) Tobin AM, Veale DJ, Fitzgerald O, Rogers S, Collins P, O'Shea D et al. Cardiovascular disease and risk factors in patients with psoriasis and psoriatic arthritis. J Rheumatol 2010;37:1386-1394.

(5) Peters MJ, van der Horst-Bruinsma IE, Dijkmans BA, Nurmohamed MT. Cardiovascular risk profile of patients with spondylarthropathies, particularly ankylosing spondylitis and psoriatic arthritis. Semin Arthritis Rheum 2004;34:585-592.

(6) Peters MJ, van Eijk IC, Smulders YM, Serne E, Dijkmans BA, van der HorstBruinsma IE et al. Signs of accelerated preclinical atherosclerosis in patients with ankylosing spondylitis. J Rheumatol 2010;37:161-166.

(7) Perk J, De BG, Gohlke H, Graham I, Reiner Z, Verschuren WM et al. European Guidelines on cardiovascular disease prevention in clinical practice (version 2012): The Fifth Joint Task Force of the European Society of Cardiology and Other Societies on Cardiovascular Disease Prevention in Clinical Practice (constituted by representatives of nine societies and by invited experts). Eur J Prev Cardiol 2012;19:585-667.

(8) Semb AG, Kvien TK, Aastveit AH, Jungner I, Pedersen TR, Walldius G et al. Lipids, myocardial infarction and ischaemic stroke in patients with rheumatoid arthritis in the Apolipoprotein-related Mortality RISk (AMORIS) Study. Ann Rheum Dis 2010;69:1996-2001.

(9) Semb AG, Kvien TK, Demicco DA, Fayyad R, Wun CC, LaRosa JC et al. Effect of intensive lipid-lowering therapy on cardiovascular outcome in patients with and those without inflammatory joint disease. Arthritis Rheum 2012;64:2836-2846.

(10) McErlane F, Gillon C, Irvine T, Davidson JE, Casson D, Dalzell AM et al. An audit of recording cardiovascular risk factors in patients with rheumatoid arthritis and systemic lupus erythematosus in centres in East Anglia and South East. Rheumatology 2008;47:1252-1254.

(11) Toms TE, Panoulas VF, Douglas KM, Griffiths H, Sattar N, Smith JP et al. Statin use in rheumatoid arthritis in relation to actual cardiovascular risk: evidence for substantial undertreatment of lipid-associated cardiovascular risk? Ann Rheum Dis 2010;69:683688.

(12) van Gammeren AJ, van GN, de Groot MJ, Cobbaert CM. Analytical performance evaluation of the Cobas 6000 analyzer - special emphasis on trueness verification. Clin Chem Lab Med 2008;46:863-871. 
(13) Roman MJ, Naqvi TZ, Gardin JM, Gerhard-Herman M, Jaff M, Mohler E. Clinical application of noninvasive vascular ultrasound in cardiovascular risk stratification: a report from the American Society of Echocardiography and the Society of Vascular Medicine and Biology. J Am Soc Echocardiogr 2006;19:943-954.

(14) Conroy RM, Pyorala K, Fitzgerald AP, Sans S, Menotti A, De BG et al. Estimation of ten-year risk of fatal cardiovascular disease in Europe: the SCORE project. Eur Heart J 2003;24:987-1003.

(15) Van GE, Laforest L, Alemao E, Davies G, Gutkin S, Yin D. Lipid-modifying therapy and attainment of cholesterol goals in Europe: the Return on Expenditure Achieved for Lipid Therapy (REALITY) study. Curr Med Res Opin 2005;21:1389-1399.

(16) Kotseva K, Wood D, De BG, De BD, Pyorala K, Keil U. Cardiovascular prevention guidelines in daily practice: a comparison of EUROASPIRE I, II, and III surveys in eight European countries. Lancet 2009;373:929-940.

(17) Lindhardsen J, Ahlehoff O, Gislason GH, Madsen OR, Olesen JB, Torp-Pedersen C et al. Initiation and adherence to secondary prevention pharmacotherapy after myocardial infarction in patients with rheumatoid arthritis: a nationwide cohort study. Ann Rheum Dis 2012;71:1496-1501.

(18) Evans MR, Escalante A, Battafarano DF, Freeman GL, O'Leary DH, Del R, I. Carotid atherosclerosis predicts incident acute coronary syndromes in rheumatoid arthritis. Arthritis Rheum 2011;63:1211-1220.

(19) Sheng X, Murphy MJ, MacDonald TM, Wei L. Effectiveness of Statins on Total Cholesterol and Cardiovascular Disease and All-cause Mortality in Osteoarthritis and Rheumatoid Arthritis. J Rheumatol 2012;39:32-40.

(20) Van Doornum S., McColl G, Wicks IP. Accelerated atherosclerosis: an extraarticular feature of rheumatoid arthritis? Arthritis Rheum 2002;46:862-873.

(21) Solomon DH, Karlson EW, Rimm EB, Cannuscio CC, Mandl LA, Manson JE et al. Cardiovascular morbidity and mortality in women diagnosed with rheumatoid arthritis. Circulation 2003;107:1303-1307.

(22) El-Barbary AM, Hussein MS, Rageh EM, Hamouda HE, Wagih AA, Ismail RG. Effect of atorvastatin on inflammation and modification of vascular risk factors in rheumatoid arthritis. J Rheumatol 2011;38:229-235.

(23) van Denderen JC, Peters MJ, van Halm VP, van der Horst-Bruinsma IE, Dijkmans BA, Nurmohamed MT. Statin therapy might be beneficial for patients with ankylosing spondylitis. Ann Rheum Dis 2006;65:695-696.

(24) Bisoendial RJ, Stroes ES, Kastelein JJ, Tak PP. Targeting cardiovascular risk in rheumatoid arthritis: a dual role for statins. Nat Rev Rheumatol 2010;6:157-164.

(25) Maki-Petaja KM, Booth AD, Hall FC, Wallace SM, Brown J, McEniery CM et al. Ezetimibe and simvastatin reduce inflammation, disease activity, and aortic stiffness and improve endothelial function in rheumatoid arthritis. J Am Coll Cardiol 2007;50:852-858.

(26) McCarey DW, Mclnnes IB, Madhok R, Hampson R, Scherbakov O, Ford I et al. Trial of Atorvastatin in Rheumatoid Arthritis (TARA): double-blind, randomised placebocontrolled trial. Lancet 2004;363:2015-2021. 
(27) Van Doornum S., McColl G, Wicks IP. Atorvastatin reduces arterial stiffness in patients with rheumatoid arthritis. Ann Rheum Dis 2004;63:1571-1575.

(28) Charles-Schoeman C, Khanna D, Furst DE, McMahon M, Reddy ST, Fogelman AM et al. Effects of high-dose atorvastatin on antiinflammatory properties of high density lipoprotein in patients with rheumatoid arthritis: a pilot study. J Rheumatol 2007;34:1459-1464.

(29) Bansback N, Ara R, Ward S, Anis A, Choi HK. Statin therapy in rheumatoid arthritis: a cost-effectiveness and value-of-information analysis. Pharmacoeconomics 2009;27:25-37. 